\title{
On the Aggregation of Tetramethyl- and Tetraethylammonium Salts of Dinonylnaphthalenesulfonic Acid in Heptane
}

\author{
Erik Högfeldt, ${ }^{a, *}$ Aveneri V. Mikulich ${ }^{b}$ and Vladimir S. Soldatov ${ }^{b}$
}

aDepartment of Inorganic Chemistry, The Royal Institute of Technology, S-10044 Stockholm, Sweden and 'Institute of Physico-Organic Chemistry, Academy of Sciences, BSSR, Minsk 220603, The Soviet Union

\begin{abstract}
Högfeldt, E., Mikulich, A. V. and Soldatov, V.S., 1988. On the Aggregation of Tetramethyl- and Tetraethylammonium Salts of Dinonylnaphthalenesulfonic Acid in Heptane. - Acta Chem. Scand., Ser. A 42: 301-303.
\end{abstract}

In recent years, vapor phase osmometry, VPO, has been used by us in order to estimate aggregation numbers of salts of long-chain amines ${ }^{1,2}$ as well as salts of dinonyl- and didodecylnaphthalenesulfonic acids in various diluents. ${ }^{3}$ In the latter case the aggregation was found to increase with water content. Recently Mikulich et al. ${ }^{4}$ communicated ion exchange and water uptake data for primary to quaternary ammonium ions on dinonylnaphthalenesulfonic aeid (HDNNS) in three diluents as well as on the solid cation exchanger KRS-8. These data were taken from Mikulich's thesis. ${ }^{5}$ In this work the aggregation numbers were also measured using VPO. The data were fitted by a simple two-parameter equation assuming the aggregation numbers of the mixed aggregates to be the arithmetic mean of those for the pure ionic forms. ${ }^{6}$ This restriction was rather severe, and an acceptable fit could only be obtained by using values for the pure ionic forms rather different from those experimentally determined. It is the purpose of this note to show that the Högfeldt three-parameter model ${ }^{7-10}$ gives a satisfactory fit, and to compare with results obtained earlier for similar systems. ${ }^{3}$

Mikulich measured the aggregation numbers for samples slightly (wet) and much (dry) dehydrated. The water content and composition were determined for each sample. The water con-

*To whom correspondence should be addressed. tent is conveniently given as the number of water molecules per sulfonate group. This quantity, $W$, is given by:

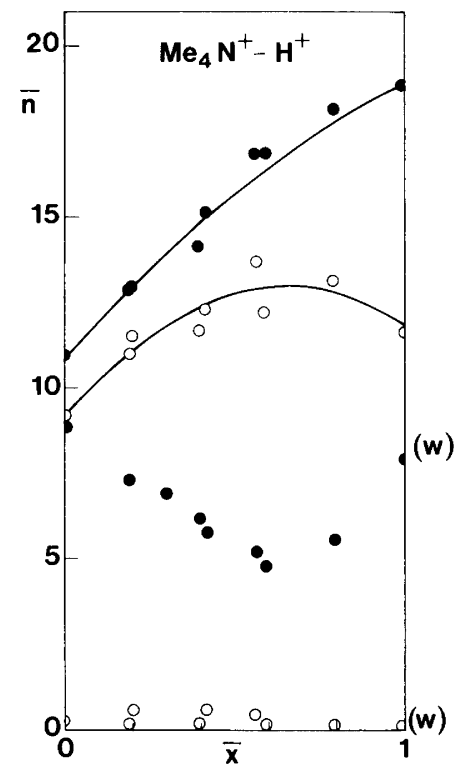

Fig. 1. $\bar{n}$ plotted against $\bar{x}\left(=\bar{x}_{\text {salt }}\right)$ for the system $\left(\mathrm{CH}_{3}\right)_{4} \mathrm{~N}^{+}-\mathrm{H}^{+}$on HDNNS in heptane. $T \approx 298 \mathrm{~K}$. $O$ dry samples; wet samples. The curve has been calculated from the model with the parameters given in Table 1. The number of water molecules per sulfonate group, $W$, is also given for each sample. 


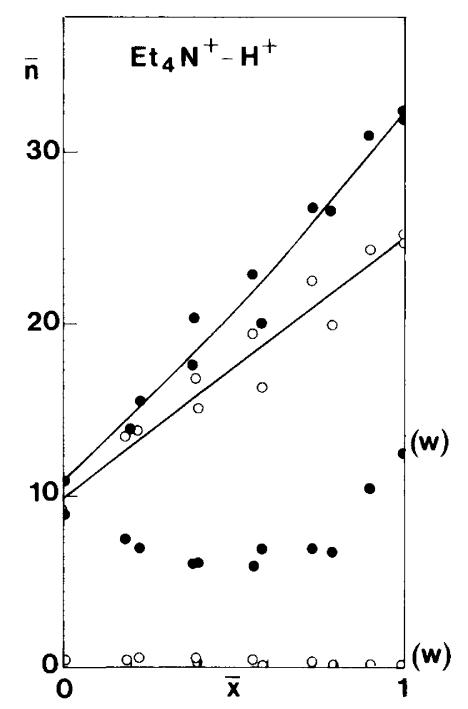

Fig. 2. $\bar{n}$ plotted against $\bar{x}\left(=\bar{x}_{\text {salt }}\right)$ for the system $\left(\mathrm{C}_{2} \mathrm{H}_{5}\right)_{4} \mathrm{~N}^{+}-\mathrm{H}^{+}$on HDNNS in heptane. O dry samples; wet samples. The curve has been calculated from the model with the parameters given in Table 1. The number of water molecules per sulfonate group, $W$, is also given for each sample.

$$
W=\left(\left[\mathrm{H}_{2} \mathrm{O}\right]_{\text {org }}-\left[\mathrm{H}_{2} \mathrm{O}\right]_{\text {dil }} /[\mathrm{HDNNS}]_{\text {tot }} .\right.
$$

The amount of water extracted by the diluent, in the present case heptane, is small. ${ }^{11}$ The results for tetramethyl- and tetraethylammonium salts are shown in Figs. 1 and 2. These figures also give the water content, $W$, of each sample. There is a considerable difference in water content between the wet and dry samples.

According to the model, a mixture of A and B can be divided into three regions, one corresponding to pure $A$, one to pure $B$ and one with both $A$ and $B$. It is assumed that any molar property, $Y$, has the value corresponding to pure $\mathrm{A}$ in the first region, $y_{\mathrm{A}}$, one corresponding to pure $B, y_{\mathrm{B}}$, in the second region and one value in the mixture, $y_{\mathrm{m}}$. Assuming that the amount of each region is proportional to the number of $A-A$ pairs, $B-B$ pairs and $A-B=B-A$ pairs, Guggenheim's zero'th approximation ${ }^{12}$ gives:

$Y=y_{\mathrm{A}} \bar{x}_{\mathrm{A}}^{2}+y_{\mathrm{B}} \bar{x}_{\mathrm{B}}^{2}+2 y_{\mathrm{m}} \bar{x}_{\mathrm{A}} \bar{x}_{\mathrm{B}}$

where $\bar{x}_{\mathrm{A}}, \bar{x}_{\mathrm{B}}$ are the equivalent fractions of the two ionic forms in the exchanger (solid or liquid).

Most data in the literature are reported as $Y=\mathrm{f}(\bar{x})$. It is then practical to introduce the equation:

$Y=y_{\mathrm{A}} \bar{x}_{\mathrm{A}}+y_{\mathrm{B}} \bar{x}_{\mathrm{B}}+\bar{B} x_{\mathrm{A}} \bar{x}_{\mathrm{B}}$

where $\bar{B}$ is an empirical constant. By leastsquares methods the two parameters $y_{A}, y_{B}$ and the empirical constant $\bar{B}$ are obtained.

The third parameter, $y_{\mathrm{m}}$ is now obtained from:

$y_{\mathrm{m}}=\frac{1}{2}\left(y_{\mathrm{A}}+y_{\mathrm{B}}+\bar{B}\right)$

which is derived by combining eqns. (1) and (2). When applying this approach to the data in Figs. 1 and 2 , the parameters given in Table 1 were obtained. The curves in Figs. 1 and 2 have been computed from the model using the parameters in Table 1. This table also gives the standard deviation, $s(\bar{n})$, which can be used as a measure of the goodness of fit.

From Figs. 1 and 2 it is evident that water promotes aggregation, in agreement with earlier findings. ${ }^{3}$ It is also seen that the increase in size is small for the HDNNS micelles but large for the ammonium salts. These latter ions might be able to build a cage of water molecules around themselves, the amount of water co-extracted with these ions being vary large. ${ }^{4}$ For the mixed aggregates the difference is also small. In mose cases $\bar{n}_{\mathrm{m}}$ is close to $\frac{1}{2}[\bar{n}(0)+\bar{n}(1)]$, as seen in Table 1 .

Table 1. Parameters obtained by least-squares fitting to eqn. (3). HDNNS in heptane. $T \approx 298 \mathrm{~K}$.

\begin{tabular}{lrcccc}
\hline System & $\bar{n}(0)^{a}$ & $\bar{n}(1)^{a}$ & $\bar{n}_{\mathrm{m}}$ & $\frac{1}{2}[\bar{n}(0)+\bar{n}(1)]$ & $s(\bar{n})$ \\
\hline$\left(\mathrm{CH}_{3}\right)_{4} \mathrm{~N}^{+}-\mathrm{H}^{+} ;$dry & 9.2 & 11.8 & 14.9 & 10.5 & \pm 0.5 \\
$\left(\mathrm{CH}_{3}\right)_{4} \mathrm{~N}^{+}-\mathrm{H}^{+} ;$wet & 10.9 & 18.9 & 16.4 & 14.9 & \pm 0.4 \\
$\left(\mathrm{C}_{2} \mathrm{H}_{5}\right)_{4} \mathrm{~N}^{+}-\mathrm{H}^{+} ;$dry & 9.9 & 24.9 & 17.6 & 17.4 & \pm 1.3 \\
$\left(\mathrm{C}_{2} \mathrm{H}_{5}\right)_{4} \mathrm{~N}^{+}-\mathrm{H}^{+} ;$wet & 11.0 & 32.3 & 19.9 & 21.7 & \pm 1.2 \\
\hline
\end{tabular}

${ }^{a} n^{7}(0)$ refers to pure HDNNS, $\bar{n}(1)$ to pure salt. 
Most authors agree on monodispersity of HDNNS and its salts in organic diluents..$^{13}$ If this is so, the parameters in Table 1 should be replaced by the nearest integers. If, on the other hand, the systems are polydisperse, as suggested by some recent low-angle scattering data, ${ }^{14}$ they represent averages.

Acknowledgement. This work is part of a program supported by the Academies of Sciences in the USSR and Sweden.

\section{References}

1. Jedináková, V. and Högfeldt, E. Chem. Scr. 9 (1976) 171.

2. Jedináková, V. and Högfeldt, E. Chem. Scr. 9 (1976) 178.

3. Kuvaeva, Z. I., Popov, A. V., Soldatov, V.S. and Högfeldt, E. Solvent Extr. Ion Exch. 4 (1986) 361.

4. Mikulich, A. V., Soldatov, V.S. and Högfeldt, E. Acta Chem. Scand., Ser. A39 (1985) 583.
5. Mikulich, A. V. Thesis, Institute of General and Inorganic Chemistry, Academy of Sciences, Minsk, BSSR 1982.

6. Soldatov, V.S. and Mikulich, A. V. Dokl. Akad. Nauk BSSR 35 (1981) 724.

7. Högfeldt, E. and Soldatov, V.S. J. Inorg. Nucl. Chem. 41 (1979) 575.

8. Högfeldt, E. Acta Chem. Scand., Ser. A33 (1979) 557.

9. Högfeldt, E. React. Polym. 2 (1984) 19.

10. Högfeldt, E. React. Polym. 7 (1988) 81.

11. Högfeldt, E. and Rasmusson, K. Svensk Kem. Tidskr. 78 (1966) 490.

12. Guggenheim, E. A. Mixtures, Clarendon Press, Oxford 1952, Chap. 4.

13. Fowkes, F. M. In: Shinoda, K., Ed., Solvent Properties of Surfactant Solutions, Marcel Dekker, New York 1967, Vol. 2, p. 65.

14. Soldatov, V.S. and coworkers. In preparation.

Received January 19, 1988. 